\title{
Spectrophotometric Analysis Of Desloratadine Multicomponent Crystal Formulation: Comparison of Conventional Methods and Chemometric Analysis
}

\author{
Syaiful Choiri, Ahmad Ainurofiq* \\ Pharmaceutical Technology and Drug Delivery, Department of Pharmacy, Universitas Sebelas Maret, \\ JL. Ir. Sutami 36A, Surakarta, Indonesia, 57126 \\ *Corresponding author email: rofiq@mipa.uns.ac.id
}

Received August 03, 2019; Accepted January 06, 2020; Available online March 15, 2020

\begin{abstract}
Multicomponent crystal (MCC) formulation consists of drug and co-former that spectrophotometrically has an interference each other. The aim of this research was to evaluate and develop the analytical method to obtain a fast, cheap, efficient, and adequate method to estimate desloratadine (DES) in MCC formulation using three different methods. Single wavelength calibration model was constructed at $290 \mathrm{~nm}$, multiple component equations was obtained from $273 \mathrm{~nm}$ and $283 \mathrm{~nm}$, and multivariate analysis consists of partial least square (PLS) and principal component analysis (PCA), a chemometric based, assisted the model selection and model calibration. Single wavelength method and multivariate analysis model had been fully validated i.e. range, specificity, accuracy, precision, limit of detection, and limit of quantification. A multivariate analysis had more adequate ability to estimate the DES and co-former in the MCC formulation.
\end{abstract}

Keywords: Desloratadine, multicomponent crystal, multivariate, PLS

\section{INTRODUCTION}

Poorly water-soluble drugs have some problems related to the bioavailability due to its solubility (Loftsson, Muellertz, \& Siepmann, 2013) e.g. desloratadine (DES) (Kolašinac et al., 2012). DES, a loratadine's derivate, has been used as a second generation of antihistamine drugs (non-sedative effect) and a high-selective of peripheral of $\mathrm{HI}$ receptor antagonist that has been proven its safety and efficacy to treat rhinitis allergy, asthma, urticarial, and anti-inflammation (Agrawal, 2001). Therefore, several approaches have been introduced such as cyclodextrin complexation (Ainurofiq \& Choiri, 2016; Ainurofiq et al., 2016), lipid formulation (Kalepu, Manthina, \& Padavala, 2013), nanoparticle (Kalepu \& Nekkanti, 2016), and crystal technology including nanocrystal (Lai et al., 2014), amorphous dispersion (Huang, Mao, Williams III, \& Yang, 2016), and crystal manipulation (Golob et al., 2016) to improve its solubility of poorly water. The multicomponent crystal (MCC) is attractive, feasible, and simple technologies compared to others crystal technologies (El-Gizawy, Osman, Arafa, \& El Maghraby, 2015; Golob et al., 2016). Meanwhile, the MCC not only improved a solubility of the drug, but also it improved stability and physicomechanic properties e.g. a compaction behavior (Ahmad Ainurofiq, 2018). A co-former as comaterial is required to form MCC formulation (EIGizawy et al., 2015; Yadav, Shete, Dabke, Kulkarni, \& Sakhare, 2009).
In the pharmaceutical formulation, an assay is an important step to determine the drug content in the formulation (Siddiqui, AlOthman, \& Rahman, 2017). Several approaches in DES assay have been reported e.g. UV spectrophotometric (Cağlar \& Oztunç, 2007; Takano, de Souza Reis, Singh, \& Lourenço, 2017) or complexation followed by the visible spectrophotometric approach to improve selectivity as the presence of matrix (Cağlar \& Oztunç, 2007; Gouda \& Kasssem, 2016), spectrofluorometric and HPLC method (El-Enany, El-Sherbiny, \& Belal, 2007). Complexation to improve selectivity is not simple and affordable approaches, and it is very depending on the kinetic or stoichiometric of reaction of DES and its ligand (Gouda \& Kasssem, 2016). A chromatography method is attractive due to a separation process, this step can improve selectivity on the drug assay (ElEnany et al., 2007), although compared to the spectrophotometric approach, it is a high cost and needs a long time to analyze. However, an assay of the drug in MCC formulations using UV spectrophotometric technique along with predetermined single wavelength is difficult due to a presence of co-former as matrix or interference (Yadav et al., 2009). Analytical problem regarding the mixture of substances can be solved by a multiple wavelength technique. In addition, the peak of specific UV band corresponding to each drug should be in a high resolution. However, overlapping band could be analysed using UV-Vis spectrophotometry (Liudmil 
Antonov \& Stefan Stoyanov, 1993). In addition, multivariate method can be easily applied for eliminating the interference of overlapping band. Until to the date, there were not yet reported simple, cheap, and fast methods to analyze DES in the MCC formulation. Therefore, a selected method or instrument that has simple, fast, cheap, and efficient characteristics is needed to conduct DES assay in an MCC formulation.

In this study, we produced the MCC formation of DES with benzoic acid (BZA) as the co-former due to a high interference in the spectrophotometric assay. The purpose of this study was to evaluate and develop the accurate, fast, simple, cheap, and efficient methods on the assay of DES in the MCC formulation as a presence of BZA as co-former at a single wavelength, multiple wavelengths, and multivariate analysis using UV spectrophotometric assay.

\section{EXPERIMENTAL SECTION \\ Materials}

DES was purchased from Xi'An Wango Biopharm Co.Ltd., (Shaanxi, China), BZA was obtained from Sigma Aldrich (St. Louis, MO), methanol from J.T. Baker (Phillipsburg, NJ), hydrochloric acid from Merck (Darmstadt, Germany)

\section{Preparation of DES MCC}

Simulation of DES MCC was performed by BZA as the co-former. An equimolar mixture of DES and BZA was dissolved in the methanol followed by an evaporation using a rotary evaporator Buchi Rotavapor R-215 (Flawil, Switzerland) at temperature $45^{\circ} \mathrm{C}$ and pressure 208 mbar. The DES-BZA MCC was obtained by grinding the dried mixture and stored in the desiccator until further analysis (Ainurofiq, Mauludin, Mudhakir, \& Soewandhi, 2018).

\section{Preparation of Standard Stock Solution}

A standard stock solution was separately prepared by weighing accurately of DES $25.0 \mathrm{mg}$ and BZA 25.0 $\mathrm{mg}$ then it transferred into a $100 \mathrm{~m}$ volumetric flask. In addition, to dissolve DES and BZA, a minimum amount of methanol was added as a co-solvent (in the final concentration, not more than 1\%). Several solvents were applied e.g. methanol, water, and $\mathrm{HCl}$ $0.1 \mathrm{~N}$ to obtain standard stock solutions of DES and BZA.

\section{UV-Band Acquisition}

A $1 \mathrm{~mL}$ of standard stock solution was transferred into a $10 \mathrm{~mL}$ volumetric flask followed the addition of methanol, water and $\mathrm{HCl} 0.1 \mathrm{~N}$, separately. Furthermore, solution scanned from 400 to $200 \mathrm{~nm}$ using a Beckman Coulter DU 720 UV-Vis Spectrophotometer (10 mm quartzcells) (Potterville, CA).

\section{One Wavelength Model Calibration}

One wavelength model calibration was conducted at $290 \mathrm{~nm}$ using $\mathrm{HCl} 0.1 \mathrm{~N}$ as a solvent. Firstly, several concentrations of calibrations solution series were prepared by dilution of standards stock solution of DES until the concentration of $5,10,12,16,20,25$, and $30 \mu \mathrm{g} / \mathrm{mL}$ was achieved. Each solution was scanned at $290 \mathrm{~nm}$. The calibration model was constructed as a function of concentration and response (absorbance). A validation of calibration model was performed i.e. linearity, range, accuracy, precision, limit of detection (LoD), limit of quantification (LoQ).

Linearity and range were performed at concentration levels of $5-30 \mu \mathrm{g} / \mathrm{mL}$. In addition, precision and accuracy were performed at 3 different concentration levels and scanned triplicates. LoD and LoQ were determined by standard deviation of blank $\left(S_{\text {blank }}\right)$ and slope (b) of the calibration model by following equations.

$$
\begin{aligned}
& \text { LoD }=3.3 \times \frac{S_{\text {blank }}}{b} \\
& \text { LoQ }=10 \times \frac{S_{\text {blank }}}{b}
\end{aligned}
$$

\section{Multiple Wavelength Model}

A multiple wavelength model was conducted at 273 and $283 \mathrm{~nm}$ using $\mathrm{HCl} 0.1 \mathrm{~N}$ as a solvent. Firstly, a 7 concentration levels of DES and BZA at response ranged from $0.2-0.8 \mathrm{AU}$ was prepared by dilution with $\mathrm{HCl} 0.1 \mathrm{~N}$. An absorptivity $\left(A_{1 \%, 1 \mathrm{~cm}}\right)$ was calculated based on response and concentration. Depending on different wavelengths of 273 and $283 \mathrm{~nm}$, two equations were constructed based on responses at different wavelengths $\left(Y_{273}\right.$ and $Y_{283}$, respectively) and $A_{1 \%, 1 \mathrm{~cm}}$ of DES (A $A_{D E S 273}$ and $A_{D E S 283}$, respectively) and $B Z A\left(A_{B Z A 273}\right.$ and $A_{B Z A 283}$, respectively).

$$
\begin{aligned}
& Y_{273}=\left(a \times A_{\text {DES273 }}\right)+\left(b \times A_{\text {BZA273 }}\right) \\
& Y_{283}=\left(a \times A_{\text {DES283 }}\right)+\left(b \times A_{\text {BZA283 }}\right)
\end{aligned}
$$

Where $a$ and $b$ are concentration of DES and ABZ, respectively. The validation of this model was performed by accuracy and precision using 3 different concentration levels of an equimolar mixture of DES and $A B Z$.

\section{Multivariate Model Calibration}

A calibration series concentration was prepared by different DES to $A B Z$ weight ratio i.e. 100:0; 90:10; $80: 20 ; 70: 30 ; 50: 50 ; 20: 70 ; 0: 100$. Each ratio was weighed accurately $25.0 \mathrm{mg}$ and transferred into a $100 \mathrm{~mL}$ volumetric flask followed by addition of $\mathrm{HCl}$ $0.1 \mathrm{~N}$. Thereafter, a dilution process was conducted until a concentration level of $25 \mu \mathrm{g} / \mathrm{mL}$ was achieved for each ratio. All solutions were scanned from 320 to $200 \mathrm{~nm}$ at a resolution of $2 \mathrm{~nm}$ using a Beckman DU 720 UV-Vis Spectrophotometer (a $10 \mathrm{~mm}$ quartz cells) (Potterville, CA). A chemometric analysis including partial least square (PLS) calibration model and principal component analysis (PCA) was applied in the multivariate analysis.

Validation in this PLS model was conducted by a cross-validation using a leave one out method. Accuracy and precision were determined by based on 
the calculating recovery between observed and predicted of cross-validation method. Linearity and range were validated based on the calibration model.

\section{Assay of DES in MCC Formulation}

A $25.0 \mathrm{mg}$ of DES MCC was weighed and transferred into a $100 \mathrm{~mL}$ volumetric flask followed by a dilution with $\mathrm{HCl} 0.1 \mathrm{~N}$ until a $25 \mu \mathrm{g} / \mathrm{mL}$ of concentration level was achieved. The solution was scanned from 320 to $200 \mathrm{~nm}$ at $1 \mathrm{~nm}$ of resolution using a Beckman DU 720 UV-Vis Spectrophotometer (10 mm quartz cells) (Potterville, CA). The DES content was determined based on validated one wavelength, multiple wavelengths, and multivariate methods and calculated based on the co-crystal formulation

\section{Data Analysis}

Calibration model was evaluated by regression test using $95 \%$ of confidence level ( $p$-value $=0.05$ ), and the intercept was not significant difference from zero $(p>0.05)$. PLS and PCA were analysed using Minitab software (version 16, Sydney, Australia). The coefficient of determination $\left(R^{2}\right)$ and root mean square of cross-validation (RMSCV) were used as criteria for a PLS analyses depending on the number of selected components.

Analysis of variance (ANOVA) was used to compare the assay test followed by t-test using $95 \%$ of confidence level ( $p$-value $=0.05)$. A one-sample t-test was implemented for comparison of predicted value by each model and theoretical value using $90 \%$ confidence level ( $p$-value $=0.1)$.

\section{RESULTS AND DISCUSSION}

In a prior study, we examined the co-former to simulate the effect of the matrix that had a high interference using UV spectrophotometer. Therefore, BZA had been selected as co-former to simulate the MCC technique. Spectrophotometer UV had been chosen as instrument due to cheap, easy and fast analysis (El-Enany et al., 2007). Des and BZA had been screened using several solvents. UV-Bands of DES and BZA using methanol, water, and $\mathrm{HCl} 0.1 \mathrm{~N}$ are presented in Figure 1. An $\mathrm{HCl}$ $0.1 \mathrm{~N}$ as the solvent was selected in an assay process of DES due to high absorptivity value. DES had a wavelength that has maximum absorbance $\left(\lambda_{\max }\right)$ using $\mathrm{HCl} 0.1 \mathrm{~N}$, methanol and water of 283,243 , and 240 , respectively and BZA had $\lambda_{\max }$ using $\mathrm{HCl} 0.1 \mathrm{~N}$, methanol, and water of 273, 272, and $273 \mathrm{~nm}$, respectively. Using methanol and water as solvents reduce the intensity of DES and induced the hypsochromic and hypochromic peak shiftings. These phenomena affected by an unprotonated of $N$ group in the molecular structure of DES, thus reduce the conjugation system (Cağlar \& Oztunç, 2007). In addition, BZA in an acidic solvent had a lower intensity, this effect was an advantage due to a lower interference if an acidic medium was used.
Three calibration methods had been used to obtain the effective and efficient to reduce the interference of BZA. The single wavelength method has been used at $290 \mathrm{~nm}$. This wavelength was selected due to a low interference of $B Z A$ response $(<2 \%)$. Using acidic medium, BZA had a low absorbance around 280 to $290 \mathrm{~nm}$, therefore at wavelength $290 \mathrm{~nm}$ BZA only interfered the DES response of $0.87 \%$. A calibration model was constructed at range $5-30 \mu \mathrm{g} / \mathrm{mL}$ and obtained a regression model based on the following equation.

$$
y=0.0274 x-0.0105\left(R^{2}=0.996\right)
$$

Where $y$ was absorbance at $290 \mathrm{~nm}$ and $x$ was concentration $(\mu \mathrm{g} / \mathrm{mL})$ of DES. This regression model was a significant model $(p<0.05)$ and an intercept was not significant $(p>0.05)$. Depending on Eq. 5, absorptivity at $1 \%(\mathrm{w} / \mathrm{v})$ concentration using $1 \mathrm{~cm}$ path-length $\left(\mathrm{A}_{1 \% 1 \mathrm{~cm}}\right)$ of DES was 274 , furthermore it reflected sensitivity of DES and not significant of random error $(p<0.05)$, respectively.

A calibration model was constructed based on the actual and predicted concentrations, thus this model has a high correlation (R) between actual and predicted by $99.80 \%$ (Figure $2 ; R^{2}=0.9961$ ). In addition, to ensure the quality of assay results this model had been validated. Validated results are presented in Table 1. The calibration model had a good linearity at range $5.06-30.36 \mu \mathrm{g} / \mathrm{mL}$ that had been proven by $\mathrm{R}^{2}$ more than 0.98 , thus this model followed a Lambert-beer law and concentration $99.6 \%$ affected the response, although $0.4 \%$ error affected by unknown variables. The calibration model had good accuracy and precision that had been proven by recovery between 98 to $102 \%$ and RSD less than $2 \%$. Although, this model had limitation i.e. the matrix interference cannot be considered though it had low interference level. Therefore, we compare the others model to estimate the effect of matrix interference.

A multiple wavelengths model can be used to estimate or compensate the effect of overlapping band because an absorbance of spectroscopy spectrum is naturally an additive effect. In multiple wavelength models, we chose at $\lambda_{\max }$ of DES and BZA in $\mathrm{HCl} 0.1 \mathrm{~N}$. Several concentrations that had response ranged from 0.2 to 0.8 has been used to determine $A_{1 \% 1 \mathrm{~cm}}$ of DES and BZA. The concentration used had good linearity $\left(R^{2}\right.$ more than 0.99). $A_{1 \% 1 \mathrm{~cm}}$ values of DES and $B Z A$ are presented in Table 2 . Based on an $A_{1 \% 1 \mathrm{~cm}}$ value, multiple component equation was constructed based on Eq. 3 and 4.

$$
\begin{aligned}
& Y_{273}=287.4 a+65.3 b \\
& Y_{283}=303.2 a+45.4 b
\end{aligned}
$$

Depending on Eqs. 6 and 7, using a mathematical substitution method, DES concentration (a) and BZA concentration (b) can be calculated. Furthermore, to ensure the quality of assay the model had been validated by accuracy and precision. This model had not suitable accuracy and precision that was $97.73 \%$ 
of recovery (outrange of $98-102 \%$ ) and $2.24 \%$ of RSD (more than 2.0\%). Based on these data (multiple wavelengths) showed that BZA had interference on
DES recovery and RSD on the other word multiple wavelength method cannot be adequate to consider the effect of overlapping DES and BZA UV-band.

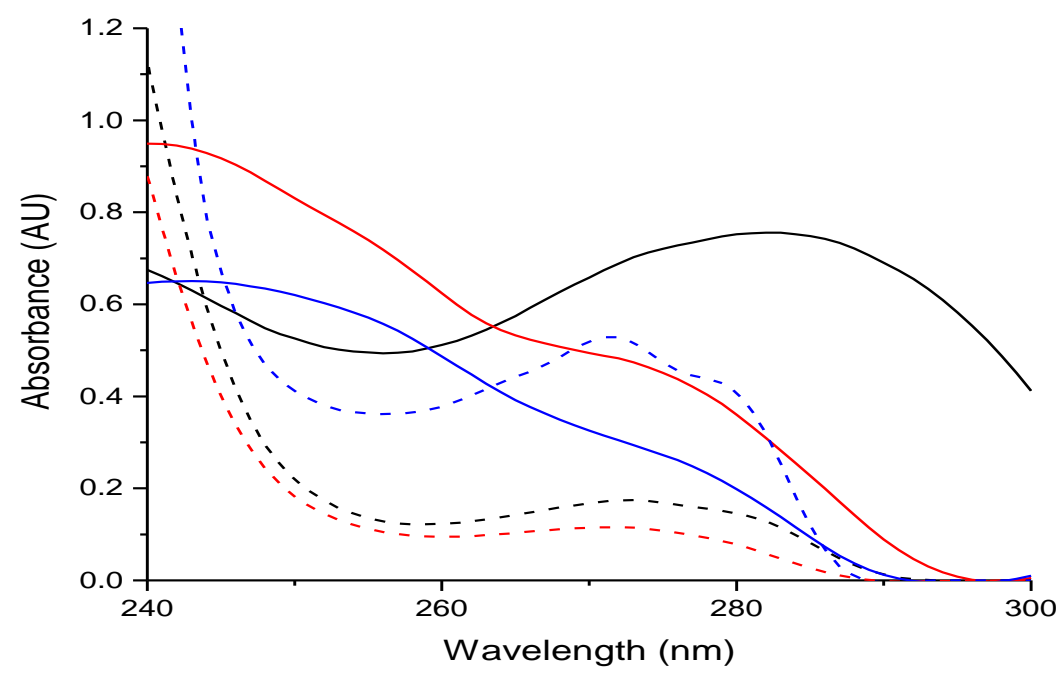

Figure 1. Spectrum UV of desloratadin (-) and benzoic acid (---) in different medium e.g. hydrochloric acid $0.1 \mathrm{~N}$ (black line), water (red line), and methanol (blue line)

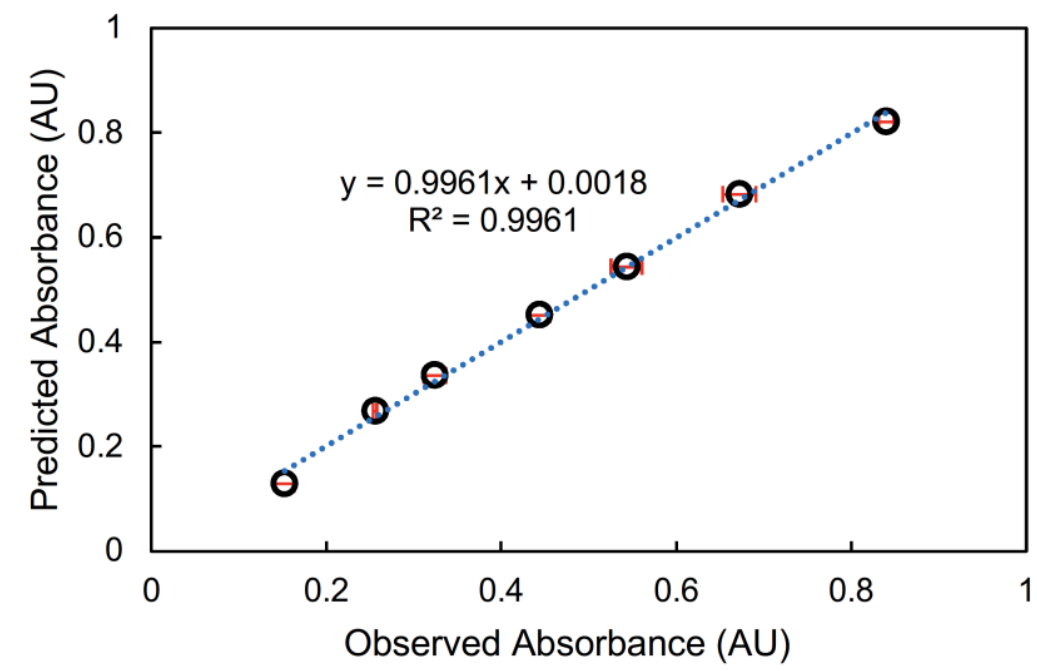

Figure 2. Calibration model of a single photometric method at a wavelength $290 \mathrm{~nm}$

Table 1. Validation parameters of single and multiple wavelength methods

\begin{tabular}{lll}
\hline Validation Parameters & Single wavelength method & $\begin{array}{l}\text { Multiple wavelength } \\
\text { method }\end{array}$ \\
\hline Range $(\mu \mathrm{g} / \mathrm{mL})$ & $5.06-30.36$ & - \\
Linearity; $\mathrm{R}^{2}$ & 0.996 & - \\
Recovery $(\%)$ & $99.97 \pm 1.39$ & $97.73 \pm 2.12$ \\
Precision $(\%)$ & 1.39 & 2.24 \\
LoD $(\mu \mathrm{g} / \mathrm{mL})$ & 0.48 & - \\
LoQ $(\mu \mathrm{g} / \mathrm{mL})$ & 1.43 & - \\
\hline
\end{tabular}

Table 2. Absorptivity $\left(\mathrm{A}_{1 \% ; 1 \mathrm{~cm}}\right)$ of desloratadine and benzoic acid at $0.1 \mathrm{~N} \mathrm{HCl}$ as medium

\begin{tabular}{ccc}
\hline \multirow{2}{*}{ API } & \multicolumn{2}{c}{$\mathrm{A}_{1 \% ; 1 \mathrm{~cm}}$ at wavelengths } \\
\cline { 2 - 3 } & $273 \mathrm{~nm}$ & $283 \mathrm{~nm}$ \\
\hline Desloratadine & $287.4 \pm 22.8$ & $303.2 \pm 24.5$ \\
Benzoic Acid & $65.3 \pm 3.0$ & $45.4 \pm 0.8$ \\
\hline
\end{tabular}




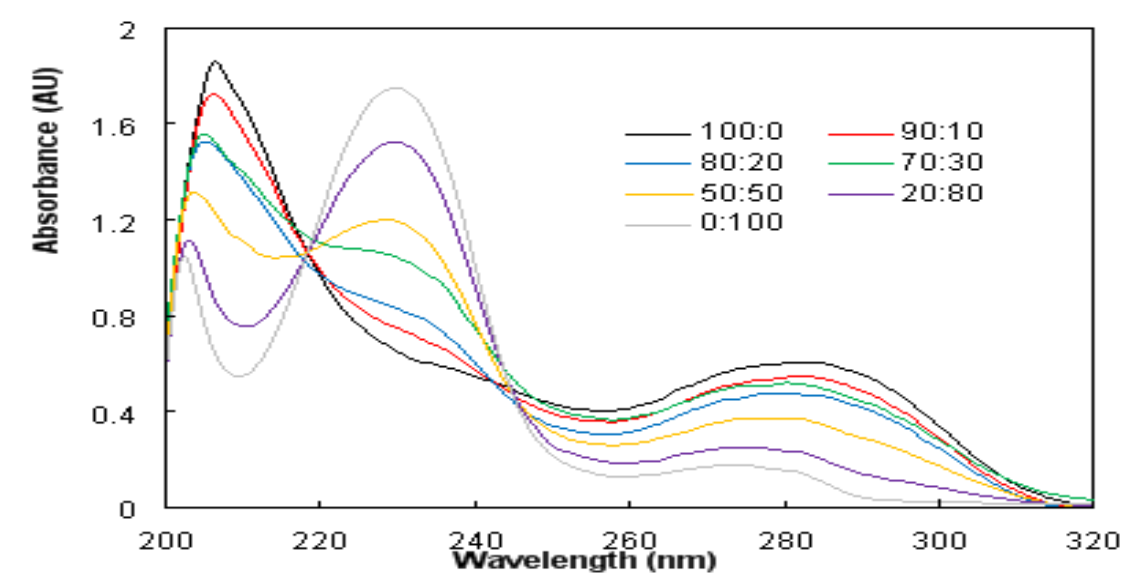

Figure 3. Spectrum UV of mixture between desloratadine and benzoic acid at several ratios

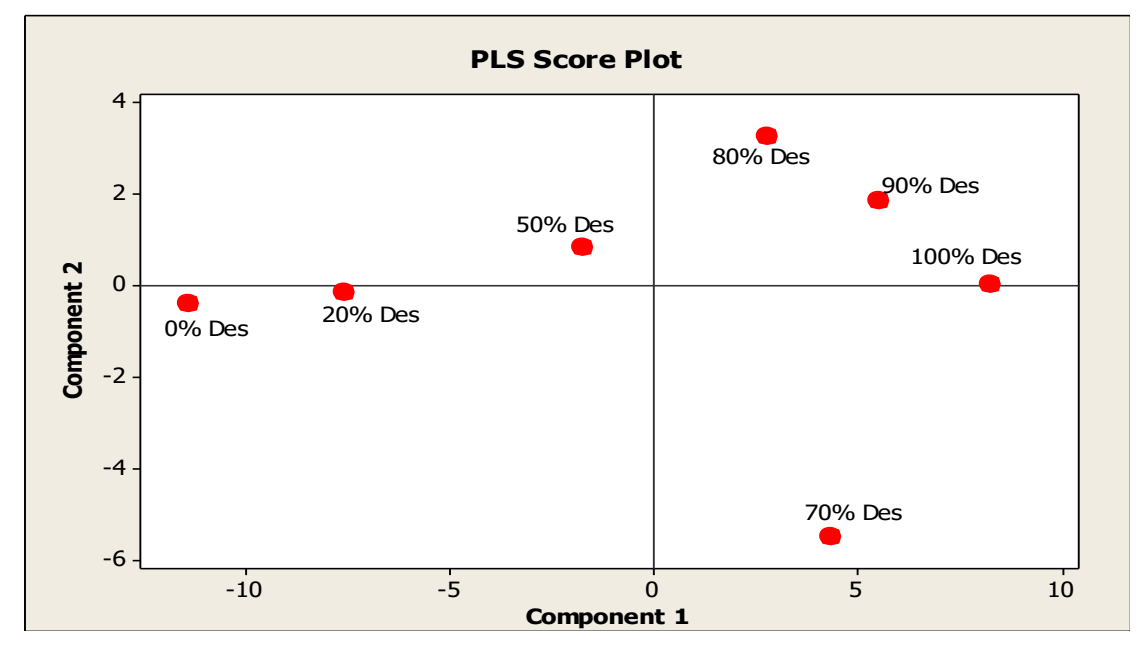

Figure 4. PLS score plot of multivariate method from 320-200 nm of UV band

A multivariate analysis based on chemometric analysis was used to estimate the Des in the co-crystal formulation. In this model, a UV band ranged from 320 to $200 \mathrm{~nm}$ was implemented. UV bands of several mixtures under different ratios are presented in Figure 3. A similar pattern of UV Band was shown at range band of $320-250 \mathrm{~nm}$, while a different pattern observed at $250-200 \mathrm{~nm}$ due to a contribution of different ratio of DES and BZA. Depending on these reasons, a multivariate analysis based on PCA to divide based on component and PLS to predict the unknown concentration of DES in the MCC formulation.

PLS and PCA are an adequate method that reduces numerous predictors as components, thus a predictive model can be simplified and has a high predictive power (Rohman, Sismindari, Erwanto, \& Che Man, 2011 ). Based on PCA, score plot showed that different pattern of UV band. UV bands of a mixture $50 \%$ DES and 50 BZA and $70 \%$ DES and $30 \%$ BZA had different patterns that were proven by different quadrants on the score plot. A similar pattern was shown by similar quadrant and vice versa (Figure 4). This result did not provide a direct implication for DES and BZA quantification. However, it provided the pattern recognition along with changes in the concentration ratio. Therefore, the unique pattern was observed at concentration in range of $50-80 \%$. A calibration model based on PLS regression was constructed based on actual value and predicted value of regression model (Figure 5a). Predicted value was calculated depending on the absorbance in each wavelength $(\mathrm{nm})$ in UV band using determined model i.e. PLS regression. A two components model was chosen in PLS regression due to the highest predicted $R^{2}(0.999)$ and the lowest predicted residual error sum square (8.126). The model was a significant term $(p<0.05)$ and the model has lowest RMSECV. A validation method based-cross validation using a leave one out method was implemented to ensure the predictive power of the model. The cross-validation model is presented in the Figure 5b. Based on this model recovery was obtained $99.58 \%$ and RSD was $0.73 \%$. The model has a good linearity at the range of DES $0 \%$ to DES $100 \%$ mixture $\left(R^{2}=0.9997\right)$. Results of the assay can be calculated based on the coefficient of PLS regression from 61 predictors and simplified to 2 predictors. 


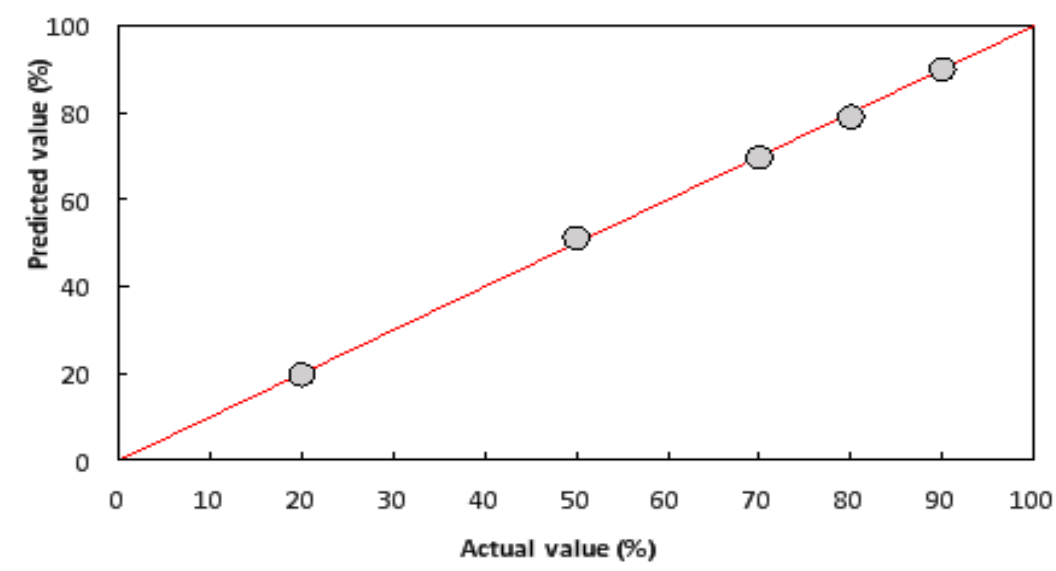

(a)

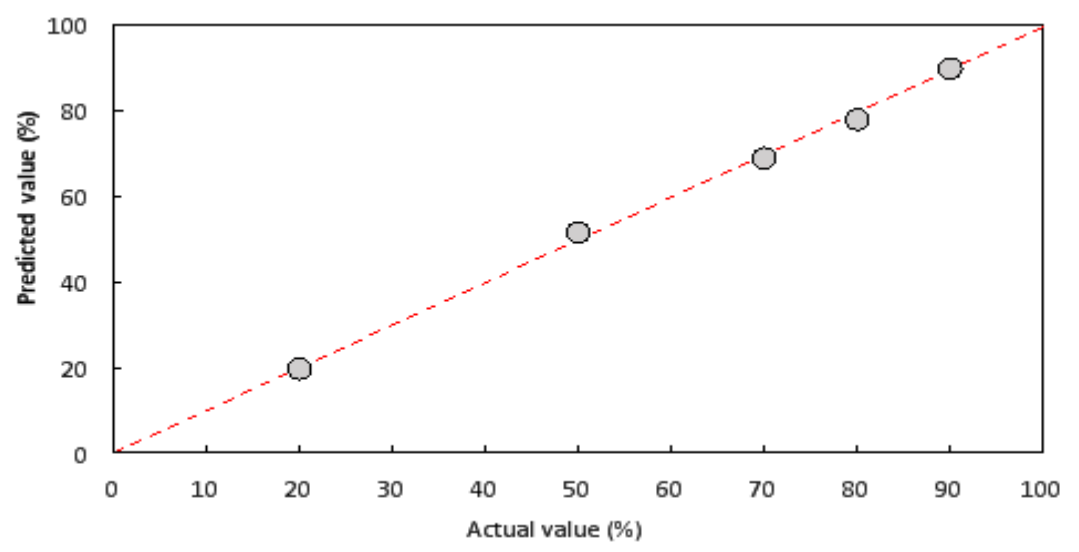

(b)

Figure 5. Calibration model (a) and cross-validation calibration model (b) of PLS based analysis using UV band ranged from 320-200 nm

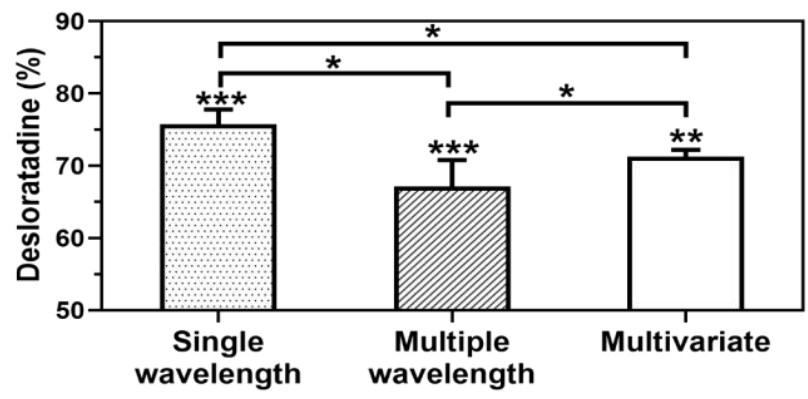

Figure 6. Assay of desloratadine in multicomponent crystal formulation using three different methods. Connected two lines implied comparison of two model *: significant different term ( $p$ $<0.05),{ }^{* *}$ : not significant different from actual concentration ( $\left.p>0.1\right)$, and ${ }^{* * *}$ : significant different from actual concentration $(p<0.1)$.

The assay of DES in the MCC formulation using three different methods was performed and the result is presented in Figure 6. Theoretically, an equimolar mixture consists of $71.22 \%$ of DES. In addition, results of three different methods were compared and a multivariate analysis showed the powerful predictive model that had a concentration of $71.30 \pm 0.90 \%$ DES in the MCC formulation ( $p>0.1)$. Although, the single and multi-wavelength model showed an undesirable DES assay in the MCC formulation $75.75 \pm 2.04$ and $67.14 \pm 3.66 \%$, respectively. A multivariate model compares the whole of UV band under range from 320 to $200 \mathrm{~nm}$, this method is powerful and adequate to estimate the DES in the MCC formulation.

\section{CONCLUSIONS}

The assay of DES in the mixture with BZA in MCC formulation was performed by three different methods i.e. single-wavelength, multi-wavelength, and multivariate based PLS and PCA. A two of these methods had been fully validated. Compared to the other method, multivariate is an adequate and 
powerful model to estimate the DES in the binary mixture or MCC formulation. Multivariate analysis based-UV spectrophotometric was simple, cheap, accurate, efficient, and adequate to estimate DES assay in the MCC formulation.

\section{REFERENCES}

Agrawal, D. K. (2001). Pharmacology and clinical efficacy of desloratadine as an anti-allergic and anti-inflammatory drug. Expert Opinion on Investigational Drugs, 10(3), 547-560. https://doi.org/10.1517/13543784.10.3.547

Ainurofiq, A. (2018). Improvement of physicochemical and technology properties of desloratadine via multicomponent crystal engineering. Dissertation.

https://digilib.itb.ac.id/index.php/gdl/view/34 311

Ainurofiq, A., \& Choiri, S. (2016). Development and optimization of a meloxicam/ $\beta$-cyclodextrin complex for orally disintegrating tablet using statistical analysis. Pharmaceutical Development and Technology, 0(0), 1-12. https://doi.org/10.1080/10837450.2016.126 4418

Ainurofiq, A., Choiri, S., Azhari, M. A., Siagian, C. R., Suryadi, B. B., Prihapsara, F., \& Rohmani, S. (2016). Improvement of meloxicam solubility using a $\beta$-cyclodextrin complex prepared via the kneading method and incorporated into an orally disintegrating tablet. Advanced Pharmaceutical Bulletin, 6(3), 399-406. https://doi.org/10.15171/apb.2016.052

Ainurofiq, A., Mauludin, R., Mudhakir, D., \& Soewandhi, S. N. (2018). Synthesis, characterization, and stability study of desloratadine multicomponent crystal formation. Research in Pharmaceutical Sciences, 13(2), 93-102.

Cağlar, S., \& Oztunç, A. (2007). A sensitive spectrophotometric method for the determination of desloratadine in tablets. Journal of AOAC International, 90(2), 372375.

El-Enany, N., El-Sherbiny, D., \& Belal, F. (2007). Spectrophotometric, spectrofluorometric and HPLC determination of desloratadine in dosage forms and human plasma. Chemical \& Pharmaceutical Bulletin, 55(12), 1662-1670.

El-Gizawy, S. A., Osman, M. A., Arafa, M. F., \& El Maghraby, G. M. (2015). Aerosil as a novel cocrystal co-former for improving the dissolution rate of hydrochlorothiazide. International Journal of Pharmaceutics, 478(2), 773-778. https://doi.org/10.1016/i.ijpharm.2014.12.0 37

Golob, S., Perry, M., Lusi, M., Chierotti, M. R., Grabnar, I., Lassiani, L., ... Zaworotko, M. J. (2016). Improving biopharmaceutical properties of vinpocetine through cocrystallization. Journal of Pharmaceutical Sciences, 105(12), 3626-3633. https://doi.org/10.1016/i.xphs.2016.09.017

Gouda, A. A., \& Kasssem, M. (2016). Novel spectrophotometric methods for determination of desloratidine in pharmaceutical formulations based on charge transfer reaction. Arabian Journal of Chemistry, 9, Supplement 2, S1712S1720.

https://doi.org/10.1016/i.arabjc.2012.04.050

Huang, S., Mao, C., Williams III, R. O., \& Yang, C.-Y. (2016). Solubility advantage (and disadvantage) of pharmaceutical amorphous solid dispersions. Journal of Pharmaceutical Sciences, 105(12), 3549-3561. https://doi.org/10.1016/i.xphs.2016.08.017

Kalepu, S., Manthina, M., \& Padavala, V. (2013). Oral lipid-based drug delivery systems - an overview. Acta Pharmaceutica Sinica B, 3(6), 361-372. https://doi.org/10.1016/i.apsb.2013.10.001

Kalepu, S., \& Nekkanti, V. (2016). Improved delivery of poorly soluble compounds using nanoparticle technology: a review. Drug Delivery and Translational Research, 6(3), 319332. https://doi.org/10.1007/s13346-0160283-1

Kolašinac, N., Kachrimanis, K., Homšek, I., Grujić, B., Đurić, Z., \& Ibrić, S. (2012). Solubility enhancement of desloratadine by solid dispersion in poloxamers. International Journal of Pharmaceutics, 436(1-2), 161-170. https://doi.org/10.1016/i.ijpharm.2012.06.0 60

Lai, F., Pini, E., Corrias, F., Perricci, J., Manconi, M., Fadda, A. M., \& Sinico, C. (2014). Formulation strategy and evaluation of nanocrystal piroxicam orally disintegrating tablets manufacturing by freeze-drying. International Journal of Pharmaceutics, 467(1-2), 27-33. https://doi.org/10.1016/i.ijpharm.2014.03.0 47

Liudmil Antonov, \& Stefan Stoyanov. (1993). Analysis of the overlapping bands in UV-Vis absorption spectroscopy. Applied Spectroscopy, 47(7), 1030-1035.

https://doi.org/10.1366/0003702934415264

Loftsson, T., Muellertz, A., \& Siepmann, J. (2013). For the special IJP issue "Poorly soluble drugs." International Journal of Pharmaceutics, 453(1), $1-2$. https://doi.org/10.1016/i.ijpharm.2013.05.0 56

Rohman, A., Sismindari, null, Erwanto, Y., \& Che Man, Y. B. (2011). Analysis of pork adulteration in beef meatball using Fourier transform infrared (FTIR) spectroscopy. Meat Science, 88(1), 91-95. https: //doi.org/10.1016/i.meatsci.2010.12.007 
Siddiqui, M. R., AlOthman, Z. A., \& Rahman, N. (2017). Analytical techniques in pharmaceutical analysis: A review. Arabian Journal of Chemistry, 10(Supplement 1), S1409-S1421. https://doi.org/10.1016/j.arabic.2013.04.016

Takano, D. E. N., de Souza Reis, P. R., Singh, A. K., \& Lourenço, F. R. (2017). Estimation of uncertainty for measuring desloratadine in tablets formulation using UV spectrophotometry. Measurement, 101, 40-44. https://doi.org/10.1016/j.measurement.2017. 01.018

Yadav, A. V., Shete, A. S., Dabke, A. P., Kulkarni, P. V., \& Sakhare, S. S. (2009). Co-Crystals: A novel approach to modify physicochemical properties of active pharmaceutical ingredients. Indian Journal of Pharmaceutical Sciences, 71(4), 359-370. https://doi.org/10.4103/ 0250-474X.57283 